\title{
Postherpetic Neuralgia: What Do We Know and Where Are We HeAding?
}

David Niv, MD, Alexander Maltsman-Tseikhin, MD, and Eric Lang, MD

Postherpetic neuralgia (PHN) remains a difficult pain problem for patients and physicians alike. This review describes the epidemiology and pathophysiology of PHN and discusses proposed mechanisms of pain generation and the various treatments currently available.

Evidence is scant for the value of surgical and procedural interventions in general, although there are numerous small studies supporting the use of specific interventions such as nerve blocks, neurosurgical procedures and neuroaugmentation.
Medical interventions, particularly the use of antidepressants and anticonvulsants remain the best-documented therapies for treating pain associated with PHN. There is good evidence that amitriptyline and gabapentin reduce pain with PHN. Topical local anesthetics, such a lidocaine, may also be helpful. The decision to use a particular agent or intervention may depend on whether there is spontaneous pain, burning or lancinating pain or numbness. Interventions with low risk, such as TENS are appropriate.

Although prevention of postherpetic neuralgia appears to be an appropriate strategy, there is little evidence to support the position that medical or interventional approaches (nerve blocks) will prevent PHN after a patient develops acute herpes zoster (HZ). Although antivirals are appropriate for acute $\mathrm{HZ}$, and the use of neural blockade and sympathetic blockade may be helpful in reducing pain in selected patients with $\mathrm{HZ}$, there is little evidence that these interventions will reduce the likelihood of developing PHN.

Keywords: Postherpetic neuralgia, acute herpes zoster, interventional pain management
Ancient chronicles contain accurate descriptions of herpes zoster (HZ). An impressive series of epidemiological, laboratory, and clinical investigations lead to the conclusion that varicella and $\mathrm{HZ}$ are the same virus $(1,2)$. According to Hope-Simpson's review (2), Ingrassi was the first to describe the features of varicella in 1553, the segmental nerve distribution of $\mathrm{HZ}$ lesions were noted by Bright in 1831 and in 1875 Steiner demonstrated the infectious nature of varicella by transmitting the disease with vesicular fluid. The Hungarian pediatrician Bokai was the first to recognize that varicella and $\mathrm{HZ}$ were manifestations of the same infectious agent (1).

The segmental distribution of $\mathrm{HZ}$ and post-herpetic neuralgia (PHN) has puzzled researchers for more than 150 years (2). Over the past 60 years, intense effort has been devoted to coping with the

From Center for Pain Medicine, TEL-AVIV Sourasky Medical Center, Sackler Faculty of Medicine, TELAVIV University, TEL-AVIV, Israel, and Pharmaceutical Licensing Group, Johnson \& Johnson, Titusville, New Jersey. Address Correspondence: David Niv, MD, FIPP, Director Center for Pain Medicine, Tel Aviv Sourasky Medical Center, 6 Weizman Street, Tel-Aviv, Israel 64239

E mail: davidniv@tasmc.health.gov.il

Funding: No financial support was obtained in preparation of this manuscript.

Conflict of Interest: None disruptive primary lesion, reducing the frequency of relapsing attacks and searching for methods of actively treating PHN. And yet, the challenge remains urgent and acute since we are still largely unable to prevent or treat the disease in spite of the promise of the new up-to-date knowledge and new information that has appeared about every aspect of PHN.

The pain of acute HZ usually subsides within 3 weeks. Whenever the primary pain of $\mathrm{HZ}$ lasts for more than four to six weeks PHN is suspected. Acute HZ pain often is accompanied by decreased quality of life. Severe acute pain interferes with patients' abilities to carry out normal activities of daily living and is associated with greater use of analgesic medications (3).

Pain persists in a chronic form in 10 $15 \%$ of patients following acute $\mathrm{HZ}$ infection $(4,5)$. The incidence of $\mathrm{HZ}$ ranges between 1.3 to 4.8 per 1,000 , depending on several predisposing factors; the most important is the age of the patient (2, 6-11). Herpes zoster is most prevalent in the 50 to 70 -year-old age group $(2,6)$. Age also influences the severity of the illness. It has been hypothesized that older patients have more severe herpes zoster infections (12), but the results of several studies have not provided uniform sup- port for this prediction. The results of these studies suggest that older age is not consistently associated with either greater acute pain severity or longer acute pain duration $(13,14)$. Moreover, older age is not consistently associated with either greater rash severity or longer rash duration (15).

The incidence of $\mathrm{HZ}$ is also higher in cancer patients and in immunosuppressive states (16-22). In the older patient the active phase tends to be more severe, with more intense pain and the incidence of PHN is greater than in the younger patient $(4,11,23)$. In one study only $4.2 \%$ of young people developed $\mathrm{PHN}$, however, the incidence increased to $47.5 \%$ at the age of 70 (23). Patients with diabetes mellitus have a higher incidence of PHN (24, 25). In addition PHN is more frequent after ophthalmic herpes than after the spinal segment type. The prevalence of PHN shows no seasonal variation and no predilection for a particular sex or race $(2,4$, $6,7,11)$.

There is some evidence that the incidence of zoster has increased in recent decades. It is likely that PHN will become more prevalent, not only because of this increased incidence of zoster but also because PHN is more likely to develop in the older individuals, whose numbers are in- 
creasing (26).

Because PHN patients suffer from physical and social disability and psychological distress and have greatly increased health care utilization as a result of chronic pain, this increase in the prevalence of $\mathrm{PHN}$ will have a major impact on public health (27).

\section{Description of the Syndrome}

The syndrome of PHN is defined as the onset of persistent pain following an attack of HZ. The transition from the one condition to the other can be difficult to define. Thus, the choice of the appropriate therapy and the interpretation of treatment results can be problematic. The time interval between "crusting' of the $\mathrm{HZ}$ blisters and the onset of PHN differs according to different studies. It has been defined as four weeks (11), six weeks (22), eight weeks (28), and even as long as six months (29).

Although postherpetic neuralgia has been defined in different ways, recent data support the distinction between acute herpetic neuralgia (within 30 days of rash onset), subacute herpetic neuralgia (30120 days after rash onset), and postherpetic neuralgia (defined as pain lasting at least 120 days from rash onset (3032). The most well established risk factors for PHN are older age, greater severity of acute pain during zoster, more severe rash, and a prodrome of dermatomal pain before onset of the rash (33). Patients with all of these risk factors may have as much as a $50-75 \%$ risk of persisting pain six months after rash onset.

The distress of the patient with PHN is the result of both pain and dysesthesias. The pain is generally described as burning and continuous in nature. There may be lancinating pain. In rare cases the pain is described as throbbing or cramping. The pain characteristically spreads along a single dermatome from the central dorsal line in a ventral direction. Often, the actual pain remains confined to a single dermatome even though there has been cutaneous spread beyond the originally affected dermatome. Later, the patient may suffer from hyperpathia related in part to a fall in the threshold to pain. Dysesthesia is the intermittent occurrence of abnormal sensations that are unpleasant and sometimes described as pain. Light touch may be intolerable to these patients. The affected area shows changes in the form of pigmentation and scarring where the ves- icles have healed. Hypalgesia, paresthesia and hyperesthesia can be noted.

\section{Pathology}

Acute HZ is characterized by necrosis and scarring of the mixed dorsal root ganglion (DRG) leading to degeneration and destruction of the emerging motor and sensory fibers (34-37). Inflammatory processes can involve the anterior and posterior horns of the spinal cord (34, 35). A mononeuritis characterized by axonal damage and even myelin disruption (38) extends peripherally from the DRG (34). The number of nerve endings originating from the skin around the lesion decreases (39).

Pathological changes include the presence of "ghost cells" in the DRG of patients with PHN (37). Deterioration of large myelinated fibers has also been demonstrated. One study analyzing autopsies of patients with PHN found characteristic atrophy of the dorsal horn to be present in PHN (40).

Despite the descriptive pathological changes noted in PHN and HZ the exact mechanism(s) of how pain is generated is unclear. In $\mathrm{HZ}$, activation of nociceptive primary afferents by direct viral attack and inflammatory changes in skin, peripheral nerves, nerve roots, posterior root ganglion, and spinal cord can explain pain in most patients. The pathophysiology of PHN may involve both peripheral and central mechanisms. In PHN there is a preferential loss of large caliber neurons. This results in a selective deficiency of large diameter neurons which can cause impairment of the segmental pain modulation system (41). According to the gatecontrol theory of pain (42), decreased activity of large nerves may allow increased rates of pain impulses reaching the dorsal horn of the spinal cord (42). In this respect, PHN may be regarded as a form of deafferentation pain.

It has also been postulated that dysesthetic pain in peripheral nerve lesions may be due to damaged or regenerating nociceptive afferent fibers (43). The existence of central mechanisms as a source of pain in PHN may account for the usual failure of attempts at curing pain through deafferenting procedures such as neurectomy, and spinothalamic tractotomy (44, 45).

Various investigators have attempted to correlate the pathology of PHN with symptoms. Morris et al (46) inves- tigated the role of primary afferent fibers with polymodal nociceptors in the various pain symptoms and signs associated with PHN. Forty-four patients with PHN affecting thoracic dermatomes were examined clinically for evidence of sensory disturbance to touch and pinprick and compared to controls (14 normal subjects and nine subjects with evidence of past $\mathrm{HZ}$ infection but no pain). The patients were then divided into three groups on the basis of their clinical symptoms and signs; those with steady, burning discomfort only; those with burning discomfort, allodynia and hyperalgesia to pinprick; and those with burning discomfort, allodynia and hypalgesia to pinprick. Indirect measurements of primary afferent fiber function was performed by measuring the neurogenic axon reflex flare to topical capsaicin using Doppler flowmetry in the five clinical groups.

The two groups with allodynia had significantly decreased neurogenic flare responses compared to $\mathrm{PHN}$ subjects without allodynia and the two control groups. These results suggest that allodynia in patients with PHN may be a consequence of disrupted function of primary afferent fibers.

In contrast, in another investigation the peripheral nervous system was studied using classical electrophysiological methods in patients with PHN, and compared with the same parameters in $64 \mathrm{HZ}$ patients without PHN (47). No disparity was found between the two groups in the mean percentage differences of the electrophysiological data for peripheral sensory fibers or between sides affected by $\mathrm{HZ}$ and healthy sides. The authors concluded that $\mathrm{HZ}$ is associated with sensory axonopathy, the severity of which is similar, on the whole, in the groups with and without PHN, and that damage to peripheral large-diameter sensory fibers is not the cause of PHN.

Rowbotham et al (48) performed sensory mapping and quantitative thermal sensory testing on 35 patients with established PHN. All subjects had pain in the torso or extremities and brush-evoked allodynia. The severity of allodynia was positively correlated with reported ongoing pain severity. As a group, subjects had a sensory deficit to thermal stimuli in PHN skin compared with unaffected mirror-image skin. However, the magnitude of the heat pain sensory deficit was inversely correlated with both pain inten- 
sity and severity of allodynia. In fact, 12 subjects had heat hyperalgesia in their region of maximum pain. Compared with the 23 subjects with heat hypalgesia, the group of 12 heat-hyperalgesic subjects had significantly higher pain ratings and allodynia severity. The investigators concluded that there is no simple relationship between loss of peripheral nerve function and spontaneous or evoked pain. Rather, the preservation of several sensory modalities in their area of maximal pain suggests that in some PHN patients, activity in primary afferent nociceptors that remain connected to both their peripheral and central targets contributes significantly to ongoing pain.

A role for adrenergic receptor activation in PHN has also been postulated. Choi and Rowbotham (49) studied the effect of adrenergic receptor activation on PHN pain and sensory disturbances. Injection of saline or an adrenergic agonist in normal skin produced mild and transient pain without development of allodynia and without affecting overall PHN pain intensity. Injection of adrenergic agonist into PHN skin increases pain, probably through direct activation of C-nociceptors in the painful skin. Increased allodynia was thought to be mediated centrally and driven by the increase in C-nociceptor input. Other investigators do not agree that nociceptive $\mathrm{C}$-fiber input has a role in the pain from PHN (50). They theorize that alterations in CNS processing recognize synaptic ties between central pain-signaling pathways and mechanoreceptive A beta-fibers, depending on afferent C-fiber degeneration rather than ongoing C-fiber input. Similarly, Baron et al (51) concluded that sensitized nociceptive C-fibers were not involved in signaling allodynia. They speculated that changes in CNS processing may occur after HZ infection that strengthen the synaptic ties between central pain signaling pathways and low threshold mechanoreceptors with Abeta fibers. Thus, an anatomical synaptic reorganization dependent on afferent C-fiber degeneration was thought to be more likely, particularly in advanced stages of PHN.

\section{THERAPY}

No definitive treatment for $\mathrm{PHN}$ is available. This may be attributed to the complex nature of the pathology. There are multiple therapies available, but each case responds in a different way and not always in a manner at all convincing to the therapist. Until 1960, the literature on PHN contained large numbers of studies and descriptions of case reports of treatments that were not conducted under controlled conditions. These included both drug therapies and surgical procedures $(8,52-57)$. No definite conclusions can be drawn from these reports. Many of the therapies were highly imaginative and included such things as cobra venom, injections of posterior pituitary extract, and diphtheria antitoxin $(8,50-57)$.

In recent years treatment has mainly centered on psychotropic drugs and on anticonvulsant medications. Among the psychotropic drugs the most effective are the tricyclic antidepressants (58-60). Research in a small group demonstrated the efficacy of amitriptyline in 11 out of 14 patients (50). Desipramine has also been found to attenuate the pain of PHN (51). Taub (63) recommended treatment with a combination of fluphenazine and amitriptyline, which has proven to be beneficial (64). Watson et al (65) examined amitriptyline in a randomized double blind study using a placebo as a control in 24 patients suffering from $\mathrm{PHN}$ for more than 3 months. A marked improvement in pain ensued, without change of the fundamental lesion, using an average dosage of $75 \mathrm{mg}$ amitriptyline. It was suggested that a therapeutic window exists and that the average dose was more effective than higher dosages. Some studies have confirmed these results $(5,66)$, others have refuted them (67). It is generally agreed that treatment with antidepressants should begin at low doses and be gradually titrated (67). Many other additional trials found evidence of improvement with tricyclic antidepressants (65, 66, 68-74). These improvements were achieved with tricyclic antidepressant medication alone $(61,70)$, or in combination with other therapies that included neuroleptic agents $(64,71)$ and acupuncture $(72,73)$.

Anticonvulsant agents were found helpful in patients with a lancinating pain component (74-77). Neuroleptic drugs such as fluphenazine and flupinedol have been tried together with anticonvulsant medications for treatment of PHN, but since there has been no report on the isolated use of each agent it is difficult to reach any conclusion as to their individual efficacy $(63,64)$. The same applies to studies that claim benefit from valproic acid when given in combination with amitriptyline (73), therefore their efficacy remains undetermined (77).

More recently, gabapentin has been proven superior to placebo in $\mathrm{PHN}$ with $43 \%$ of patients reporting at least moderate improvement (versus 12\% with placebo). Because it appears to have fewer side effects than antidepressants, it has been suggested as a first-line treatment for this condition. A dose of $3500 \mathrm{mg} /$ day was the target dosage in the trial above, and many patients reached that dose $(78,79)$.

Gabapentin appears to be effective and well tolerated for the short-term treatment of PHN. However, future controlled studies are needed to determine whether the effectiveness of gabapentin for PHN is maintained for more than 2 months and to establish the optimal dose of gabapentin with that of other pharmacologic agents used for the treatment of PHN (80, 81).

An alternative approach using pregabalin was studied recently. It was reported that the treatment was safe and efficacious in relieving PHN pain and sleep interference (82). It was also noted that the global improvement was greater than a treatment with placebo.

Niv et al (77) attempted to find a correlation between the management of PHN and the characteristics of the PHN pain. They suggested that a burning type of pain, which appears in approximately $70 \%$ of the patients, would react effectively to amitriptyline treatment. In contrast pain with lancinating or stabbing/ pinprick characteristics would be managed effectively with anticonvulsant drugs such as carbamazepine or clonazepam. Dysesthetic sensations were reduced with the use of phenothiazine such as fluphenazine.

Vitamin therapies also have been proposed. An encouraging anecdotal account of success with systemic administration of vitamin E, a potent antioxidant was reported (83), however, this treatment has since been abandoned.

It is possible to treat the acute pain of HZ by local or regional anesthesia; although blocking the somatic nerve supply temporarily alleviates $\mathrm{PHN}$, there is little evidence of any lasting benefit from a somatic or sympathetic nerve block for treatment PHN (84). Furthermore, there are just not enough adequately controlled studies to warrant approbation of any one of these procedures. Sympathetic block 
has been evaluated for treatment of PHN in large groups but provided relief in less than $50 \%$ of the participants (85-87). Injection of steroids into the epidural space or intrathecally, both with or without local anesthetic supplement gave temporary relief to a minority of patients $(77,88)$. Local injection of these substances was only partially palliative in up to $70 \%$ of those treated (89-91).

Various topical treatments for PHN have been studied. These include: capsaicin, EMLA cream, lidocaine patch, and aspirin/diethyl ether mixture (92-98). Capsaicin, a neuropeptide extracted from hot pepper, has been shown to reduce and eliminate the accumulation of substance $\mathrm{P}$, and possibly other neurotransmitters in peripheral sensory nerves $(99,100)$. Capsaicin ointment must be rubbed in four to five times daily for at least a month, even if no signs of improvement are seen, prior to determining that the treatment is a failure $(92,101)$. Topical capsaicin is not associated with any severe systemic adverse effects. However, stinging and burning, particularly during the first week of therapy, is reported by many patients (92).

Watson and coworkers reported on capsaicin treatment of 33 patients (101). Twenty-four patients completed the course of four weeks; of these, 55\% showed good to excellent results. Side effects of the treatment included an unbearable burning sensation that caused nine patients in the study to withdraw within the first three days. EMLA cream is an acronym for eutectic mixture of local anesthetics. It contains lidocaine and prilocaine in an optimized mixture that enhances dermal uptake of both agents. EMLA penetrates the dermis after an application period of one to two hours. Several studies demonstrated that EMLA is beneficial in some patients with PHN $(93,102)$.

Rowbotham et al (97) investigated $5 \%$ lidocaine gel or vehicle applied simultaneously to both the area of pain due to PHN and to the contralateral mirror-image unaffected skin. Patients with cranial PHN and those with torso or limb PHN favored local drug application. Remote lidocaine application to mirror-image skin was no different from placebo. No systemic adverse effects were reported and blood levels did not exceed $0.6 \mathrm{microgram} / \mathrm{ml}$. In a second study topically applied 5\% lidocaine in the form of a non-woven polyethylene adhesive patch was used to cover the painful area (98). All subjects had allodynia on examination. Patches, covering a maximum of $42 \mathrm{~cm}^{2}$ were applied to cover the area of greatest pain as fully as possible. Lidocaine containing patches significantly reduced pain intensity. The highest blood lidocaine level measured was 0.1 micrograms $/ \mathrm{ml}$, indicating minimal systemic absorption of lidocaine. Patch application was without systemic side effect and well tolerated when applied on allodynic skin.

In another trial the efficacy of topical aspirin/diethyl ether mixture in the treatment of $\mathrm{HZ}$ and PHN was evaluated in a double-blind crossover placebo-controlled study as compared with indomethacin and diclofenac drug/ether mixtures (95). The study included 37 patients (15 with $\mathrm{HZ}$ and 22 with PHN). Comparative treatment results showed that only aspirin (but not indomethacin and diclofenac) was beneficial in both groups. Good-toexcellent results were achieved by $87 \%$ of $\mathrm{HZ}$ patients and by $82 \%$ of PHN patients treated with the aspirin/diethyl ether mixture. Similar results were noted with aspirin in chloroform (103). The mechanism responsible for the analgesic properties of aspirin is probably not the same as that responsible for its anti-inflammatory properties.

Other experimental modalities for treatment of PHN have been reported. Low energy laser therapy was investigated as a primary treatment during the acute pain phase of $\mathrm{HZ}$ to reduce incidence of PHN and in the treatment of PHN itself $(104,105)$. The authors reported improvement in approximately $60 \%$ of the patients with PHN. Sympathetic ganglion block (using alcohol) on PHN left untreated for more than six months was evaluated in a retrospective study (106). One year following the onset, the disease was nearly or completely cured in nine of 37 patients $(24 \%)$ treated with sympathetic ganglion block with alcohol and in six of $34(17.6 \%)$ without the treatment. The difference may not be clinically significant, and further research is needed before recommending either of these modalities.

Several novel methods of treating PHN have emerged. Interest in the role of the $N$-methyl-D-aspartate (NMDA) receptor has lead to the use of NMDA antagonists for treating PHN. The effect of continuous subcutaneous infusions of ketamine on nerve injury pain was exam- ined in patients with PHN (107). Ketamine was administered continuously in increasing doses using a portable infusion pump for a total of seven days and nights. Relief of continuous pain, as evaluated daily by visual analogue scales, was observed at the infusion rate of $0.05 \mathrm{mg} /$ $\mathrm{kg} / \mathrm{hr}$, but was most marked during infusion of $0.15 \mathrm{mg} / \mathrm{kg} / \mathrm{h}$. All patients reported that ketamine reduced the severity of continuous pain as well as reduced the severity and number of attacks of spontaneous pain. Allodynia was maximally reduced $59-100 \%$ after one week infusion of $0.15 \mathrm{mg} / \mathrm{kg} / \mathrm{h}$. Common side effects were itching, fatigue and dizziness.

In a further trial of ketamine, pain and sensory thresholds were tested before and after intravenous administration of ketamine $(0.15 \mathrm{mg} / \mathrm{kg})$, morphine $(0.075$ $\mathrm{mg} / \mathrm{kg}$ ) or saline in 8 patients with $\mathrm{PHN}$ (108). Neither ketamine nor morphine significantly changed the thresholds for warm, cold, heat pain or tactile sensation. However, ketamine normalized abnormal heat pain sensation in four patients, possibly due to a central effect. Ketamine, but not morphine, produced significant relief of pain. Allodynia was inhibited by ketamine as well as by morphine. Windup-like pain (pain evoked by repeatedly pricking the affected skin area) was significantly inhibited by ketamine, but significantly aggravated by morphine. Side effects were observed in all the eight patients after injection of ketamine and in 6 patients after injection of morphine.

Suzuki et al (109) reported the use of dextromethorphan, a non-selective NMDA receptor antagonist, in 25 patients with PHN. A decrease in pain intensity and alleviation of allodynia were observed in nine patients (36\%). Side effects with no severe cases occurred in eight patients $(32 \%)$, and these were mainly digestive symptoms.

Various forms of stimulation have been used to treat PHN. These include: counter irritation, transcutaneous electrical nerve stimulation (TENS), acupuncture, spinal cord stimulation, and deep brain stimulation. Taverner (110) found counter irritation effective as a method of pain relief in 12 out of 16 patients with PHN using repeated spraying of the affected skin with ethyl chloride.

Further experience in this field was gained using TENS. Niv et al (77) reported a $60 \%$ success rate in decreasing pain with TENS patients whose skin sensation 
was normal to pinprick, but only a $30 \%$ success rate in patients with numbness of the skin. In previous studies a $30 \%$ success rate was reported, however, patients were not stratified according to skin sensation (111). The analgesic effect of TENS maintained itself for several hours after the treatment. Other investigators have also had positive results with TENS (44, $112,113)$. However, randomized studies comparing TENS with clomipramine and carbamazepine reported no advantage with TENS (114). Other stimulation treatments have met with little success.

Peripheral treatment by ultrasound was not beneficial (115); and, similarly, no difference could be found between acupuncture and placebo (116). Spinal cord stimulation has been reported as helpful, however, the majority of the studies are lacking detail or poorly designed. In a study of long-term results in $70 \mathrm{pa}-$ tients, only two showed objective signs of improvement while 14 reported subjective improvement (117). There is very little published information concerning attempts at deep brain stimulation for PHN. Stimulation of the ventro-posteromedial nucleus has been reported as beneficial in $30 \%$ of treated PHN sufferers $(118,119)$. At present, this method should be regarded as experimental.

A wide variety of surgical interventions have been tried as treatment for PHN but no single operational procedure design stands out as a solution to the problem. Most reports mention a small number of patients. Numerous papers on these procedures have been presented and most report a minute benefit (44, $120,121)$. Surgical lesioning has been attempted and tried at multiple levels, starting from the periphery, with procedures such as undermining of the skin (success rate of 30\%) (122) and surgical skin shaving (success rate of 25\%) (123).

Browder and Deveer (54) reviewed the disappointing results of cordotomy, rhizotomy and sympathectomy for PHN, but were in favor of excision of the whole affected area. Other approaches to brain stem structures have been attempted including: trigeminal tractotomy, mesencephalotomy, retrogasserian rhizotomy, avulsion of the supraorbital nerve and greater superficial petrosal neurectomy $(44,121)$. Such radical surgery has brought relief to a number of isolated cases in which the surgical procedure was undertaken as a last desperate effort. Recog- nizing the rate of recurrence and the potentially extreme morbidity, resorting to surgical operations of these dimensions must be limited to the severest cases, having the poorest quality of life due to pain.

A method of chemically lesioning the peripheral nerve was reported through the use of adriamycin (124). Adriamycin, an anthracycline antineoplastic agent, can swiftly be transported to the sensory or somatic motor neurons by way of axoplasmic transport when injected into the subepineurium of the trigeminal nerve or sciatic nerve in experimental animals. It is consequently able to induce degeneration of the neurons without any systemic side effects. Intraneural injection of this agent was carried out for the treatment of a total of 22 patients presenting with intractable neural dysfunction (including seven with PHN). The nerve that innervated the affected site was exposed under local anesthesia and Adriamycin was injected into the subepineurium. Results of the treatment after average follow-up periods of 21.5 months demonstrated that of 12 patients with neuralgia, good or fair results were obtained in $67.7 \%$. There were no changes in symptoms in four cases $(33.3 \%)$. No major complications were encountered during these procedures and once symptoms had disappeared after the treatment, no recurrence of symptoms was experienced. Further research is required before this method should be recommended.

Dorsal root entry zone lesions (DREZ operation) have been utilized with varying results and severe complications in the treatment of PHN. Friedman and Nashold reported immediate analgesia after this procedure in 17 cases of refractory PHN; however, pain recurred within two months in three instances. In the remainder, good analgesia lasted between six to 25 months (125). More recently, Gorecki and Nashold (126) reported the results of 101 DREZ operations performed since 1982. Between 1982 and 1988, radiofrequency lesions were made using a straight electrode in the trigeminal nucleus extending from the $\mathrm{C} 2$ root to the obex. Complications included ipsilateral arm ataxia due to spinocerebellar tract injury and ipsilateral lower limb weakness from the pyramidal tract. The former occurred at least transiently in $90 \%$ of cases. The electrode employed from 1988 to 1989 had proximal insulation protecting the spinocerebellar tract. Since 1989, a 90-de- gree bend was added to the electrode to allow better placement. The newest electrodes were used in 46 procedures; with these ataxia was seen in $39 \%$. In PHN, $71 \%$ of the patients stated excellent or good relief. In contrast, Rath and coworkers (127) performed 12 procedures on patients with PHN and reported continuous marked improvement after DREZ lesions in only two out of ten patients (mean follow up: 52 months). The authors noted that DREZ lesions appeared to be an effective procedure in patients with pain related to root avulsion and paraplegia. In contrast, it was less successful for painful states due to PHN.

\section{Prevention}

Perhaps, the optimal approach to PHN should be prevention, the thought being that appropriate treatment in the acute phase of $\mathrm{HZ}$ might circumvent the chronic pain associated with PHN. Various treatments have met with mixed results. Antiviral drugs, while ameliorating the acute pain of $\mathrm{HZ}$ prevented chronic pain in some studies but not others $(23,128-132)$. Similar mixed results were found in studies of steroid therapy $(28,133-135)$. It appears that the effectiveness of treatment increases if the patients are treated early after the onset of acute symptoms of $\mathrm{HZ}$, while the problem is still localized to the periphery of the damaged nerve. This impression is supported by recent theories which claim that the interruption of the nociceptive impulses, which travel along the nerve, is not only a symptomatic cure, but also can help prevent transformation to a chronic pain state (136).

Winnie and Hartwell (137) examined the relationship between time of treatment of HZ with sympathetic blockade and prevention of PHN in a retrospective review of 122 patients treated at variable intervals after the onset of HZ. Data tabulated included the duration of symptoms at the time of treatment, the number of sympathetic blocks required to provide relief and the efficacy of the sympathetic blockade in terminating the acute phase of $\mathrm{HZ}$ and then preventing the development of PHN. The authors determined that sympathetic blocks terminated the pain of acute herpes zoster and prevented or relieved PHN in more than $80 \%$ of patients treated within two months of the onset of the acute phase of the disease, after which time the success rate decreased 
drastically. The benefit was hypothesized to be due to a restoration of intraneural blood flow, thus preventing the death of large fibers and avoiding the development of PHN. If sympathetic blocks were to be carried out after two months, the damage to the large fibers would be irreversible and this therapeutic modality would not be able to prevent the development of PHN.

Not all investigators agree that sympathetic ganglion block can prevent PHN . A recent literature review (138) examined the role of sympathetic block in the prevention of PHN. A total of 84 references were reviewed. The opinion of the medical community is divided on the role of sympathetic block in preventing $\mathrm{PHN}$ because of the lack of controlled trials and the conflicting retrospective reports as to its effectiveness. While many reports promote the early use of sympathetic blocks during $\mathrm{HZ}$ to prevent $\mathrm{PHN}$, others deny their value. Despite this degree of uncertainty, the seriousness of PHN may indicate early sympathetic block in addition to treatment with antiviral agents during HZ. This choice to provide sympathetic block remains a clinical decision; large controlled trials are needed to provide the necessary scientific evidence.

Pre-emptive analgesia has been investigated as a method of avoiding central sensitization in acute pain states (139, 140). Pain of peripheral origin is amplified by central sensitization, and this amplification appears to be maintained for as long as the peripheral source is present. Possibly, the aspect of central sensitization in $\mathrm{HZ}$ that leads to the development of PHN could be avoided through the administration of a prolonged, continuous somatic nerve block. Alternatively, the development of techniques for blocking the central sensitization process itself (e.g., NMDA-channel antagonists) may provide a new tool in the future. The ultimate importance of this approach, however, depends on the degree of amplification caused by central sensitization. This parameter remains unknown.

\section{CONCLUSION}

Clearly, we still have much to learn. Studies investigating the pathophysiology of $\mathrm{HZ}$ and $\mathrm{PHN}$ may prove to be beneficial in developing better treatments. Antiviral agents are useful in acute $\mathrm{HZ}$ and my help prevent PHN. Sympathetic blocks also appear to be warranted in the prevention of PHN in some cases, but this remains a clinical decision, as there is little scientific evidence to support the procedure. Local treatments like capsaicin and EMLA have been demonstrated to be helpful in some patients with PHN. Tricyclic antidepressants and anticonvulsant drugs, particularly gabapentin, have been demonstrated to be helpful in scientific studies and remain first line therapy for PHN.

Although monotherapy is commonly applied, no single best treatment for PHN has been identified. Nevertheless, appropriate therapy includes attention to psychosocial factors as well as medical treatment with gabapentin and recently pregabalin (anticonvulsants) and transdermal lidocaine (topical local anesthetics).

In 1796 the French writer Se'bastienRoch Nicolas de Chamfort wrote: "Philosophy, like medicine, has plenty of drugs, few good remedies, and hardly any specific cures." To date, we do not have a panacea. Hopefully, we have made some progress.

\section{Author Affiliation: \\ David Niv, MD \\ Director Center for Pain Medicine \\ Tel Aviv Sourasky Medical Center \\ 6 Weizman Street, Tel-Aviv \\ Israel 64239 \\ Email: davidniv@tasmc.health.gov.il}

Alexander Maltsman-Tseikhin, MD

Pharmaceutical Licensing Group

Johnson \& Johnson

PO Box 300

Mail Stop 2628

Raritan, New Jersey 08869

\section{Eric Lang, MD}

Pharmaceutical Licensing Group

Johnson \& Johnson

P.O. Box 300

Mail Stop 2628

Raritan, New Jersey 08869

\section{REFERENCES}

1. Bokai J. Das Auftreten der Schafblattern unter be sonderen Umstanden. Ungar Arch Med 1892; 1:159-161.

2. Hope-Simpson RE. The nature of herpes zoster: A long term study and a new hypothesis. Proc R Soc Med 1965; 58:9-20.

3. Mauskopf J, Austin R, Dix LP et al. Estimating the value of a generic quality-of-life measure. Med.Care, 1995; 33:4:AS195AS202.

4. Burgoon CF, Burgoon JS, Baldridge GD. The natural history of herpes zoster. JAMA 1957; 164:265-269.

5. Weis 0 , Swiratanakul K, Weintraub M. Treatment of post herpetic neuralgia and acute herpetic pain with amitriptyline and prophenazine. S Afr Med J 1982; 62:274275.

6. Ragozzino MW, Meltron LJ, Kurland LT et al. Risk of cancer after herpes zoster: A population based study. N Engl / Med 1982; 307:393-397.

7. Ragozzino MW, Meltron LJ, Kurland LT et al. Population based study of herpes zoster and its sequelae. Medicine-Baltimore 1982; 61:310-316.

8. De Moragas JM, Kierland RR. The outcome of patients with herpes zoster. Arch Dermatol 1957; 75:193-196.

9. Hope-Simpson RE. Postherpetic neuralgia. J R Coll Gen Pract 1975; 25:571-575.

10. Molin L. Aspects of the natural history of herpes zoster. A follow-up investigation of outpatient material. Acta Derm Venereol 1969; 49:569-583.

11. Rogers RS III, Tindall JP. Geriatric herpes zoster. J Am Geriair Soc 1971; 19:495-504.

12. Higa K, Mori M, Hirata K et al. Severity of skin lesions of herpes zoster at the worst phase rather than age and involved region most influences the duration of acute herpetic pain. Pain 1997; 69:245-253.

13. Dworkin RH, Perkins FM, Nagasako EM. Prospects for the prevention of postherpetic neuralgia in herpes zoster patients. Clin J Pain 2000; 16:S90-S100.

14. Haanpaa M, Laippala P, Nurmikko T. Pain and somatosensory dysfunction in acute herpes zoster. Clin J Pain 1999; 15:50-58.

15. Decroix J, Partsh H, Gonzalez R et al. Factors influencing pain outcome in herpes zoster observational study with valaciclovir. J Eur Acad Dermatol Venereol 2000; 14: 22-33.

16. Cupps TR, Silverman GJ, Fauci AS. Herpes zoster in patients with treated Wegener's Granulomatosis. A possible role for $\mathrm{cy}$ clophosphamide. Am J Med 1980; 69:881885.

17. Feld R, Evans WK, De Boer G. Herpes Zoster in patients with small cell carcinoma of the lung receiving combined modality treatment. Ann Inter Med 1980; 93:282283.

18. Mazur M, Dolin R. Herpes zoster at the $\mathrm{NIH}$ : A 20-year experience. Am J Med 1978; 


\section{5:738-744.}

19. McKendell RR, Klawans HI. Nervous system complications of varicella zoster virus. In Vikken PJ, Bruyn GW (eds.) Handbook of Clinical Neurology. Amsterdam, North Holland 1978; 34:161-183.

20. Moutsopoulos HM, Gallagher JD, Decker $\mathrm{Jl}$ et al. Herpes Zoster in patients with systemic lupus erythematosus. Arthritis Rheum 1978; 21:798-802.

21. Rifkind D. The activation of varicella zoster virus infection by immunosuppressive therapy. J Lab Clin Med 1966; 68:463-474.

22. Schimpff S, Serpick A, Stoler B et al. Varicella Zoster infections in patients with cancer. Ann Intern Med 1972; 76:241-254.

23. Boon R. Efficacy and safety of famciclovir in the treatment of Herpes Zoster. In Proceedings of the International Conference on the Varicella Zoster Virus, Paris, 1995.

24. Brown GR. Herpes Zoster: Correlation of age, sex, distribution and associated disorders. South Med J 1976; 69:576-578.

25. McCulloch DK, Fraser DM, Duncan LP. Shingles in diabetes mellitus. Practitioner 1982; 226:531-532.

26. Schmader K, George LK, Burchett BM et al. Race and stress in the incidence of herpes zoster in the elderly. J Am Geriatr Soc 1998; 46:973-977.

27. Watson CPN, Watt VR, Chipman M et al. The prognosis with postherpetic neuralgia. Pain 1991; 46:195-199.

28. Eaglestein WH, Katz R, Brown JA. The effects of early corticosteroid therapy on the skin eruption and pain of herpes zoster. JAMA 1970; 211:1681-1683.

29. Riopelle JM, Naraghi M, Grush KP. Chronic neuralgia incidence following local anesthetic for herpes zoster therapy. Arch Dermatol 1984; 120:747-750.

30. Dworkin RH, Portenoy RK. Proposed classification of herpes zoster pain. Lancet 1994; 343:1648.

31. Desmond RA, Weiss HL, Arani RB et al. Clinical applications for change-point analysis of herpes zoster pain. / Pain Symptom Manage 2002; 23:510-516.

32. Johnson RW, Dworkin RH. Treatment of herpes zoster and postherpetic neuralgia. BMJ 2003; 326:748-750.

33. Dworkin RH, Schmader KE. Epidemiology and natural history of herpes zoster and postherpetic neuralgia. In Watson CPN, Gershon AA (eds.) Herpes Zoster and Postherpetic Neuralgia 2nd ed., New York, Elsevier Press, 2001, pp 39-64.

34. Denny-Brown D, Adams RD, Fitzgerald PJ. Pathologic features of herpes zoster: A note on "geniculate" herpes. Arch Neurol Psychiat 1944; 51:216-231.

35. Head H, Campbell AW. The pathology of herpes zoster and its bearing on sensory localization. Brain 1900; 23:353-523.

36. Juel-Jensen BE, MacCallum OF. Herpes Simple Varicella and Zoster. Philadelphia, Lippincott Williams and Wilkins, 1972, pp 127-132.
37. Smith FP. Pathological studies of spinal nerve ganglia in relation to intractable in tercostals pain. Surg Neurol 1978; 10:5053.

38. Esiri MM, Tomlinson AH. Herpes Zoster. Demonstration of virus in trigeminal nerve and ganglion by immunofluorescence and electron microscopy. J Neurol Sci 1972; 15: 35-48.

39. Muller SA, Winkelmann RK. Cutaneous nerve changes in zoster. J Invest Dermatol 1969; 52:71-77.

40. Watson CPN, Deck JH, Morshead C et al. Post-herpetic neuralgia: further post-mortem studies of cases with and without pain. Pain 1991; 44:105-117.

41. Noordenbos W. Problems pertaining to the transmission of nerve impulses which give rise to pain. Pain (Amsterdam) 1959; 1:4-10, 68-80.

42. Melzac R, Wall PD. Pain mechanisms: A new theory. Science 1965; 1950:971-979.

43. Watson CPN, Morshead C, Van der Kooy D et al. Post herpetic neuralgia: post-mortem analysis of a case. Pain 1988; 34:129138.

44. Long DM. Pain of peripheral nerve injury. In Youmans JR (ed.) Neurological Surgery. Philadelphia, WB Saunders, 1982, pp 3641-3643.

45. Pappagallo M, Campbell JN. Chronic opioid therapy as alternative treatment for post-herpetic neuralgia. Ann Neurol 1994; $35: \mathrm{S}_{54}-\mathrm{S} 56$.

46. Morris GC, Gibson SJ, Helme RD. Capsaicin-induced flare and vasodilatation in patients with post-herpetic neuralgia. Pain 1995; 63:93-101.

47. Mondelli M, Romano C, Della Porta P et al. Electrophysiological findings in peripheral fibers of subjects with and without postherpetic neuralgia. Electroencephalogr Clin Neurophysiol 1996; 101:185-191.

48. Rowbotham MC, Fields HL. The relationship of pain, allodynia and thermal sensation in post-herpetic neuralgia. Brain 1996; 119:347-354.

49. Choi B, Rowbotham MC. Effect of adrenergic receptor activation on post-herpetic neuralgia pain and sensory disturbances. Pain 1997; 69:55-63.

50. Baron R, Saguer M. Mechanical allodynia in post-herpetic neuralgia: Evidence for central mechanisms depending on nociceptive C-fiber degeneration. Neurology 1995; 45:S63-S65.

51. Baron R, Saguer M. Postherpetic neuralgia. Are C-nociceptors involved in signaling and maintenance of tactile allodynia? Brain 1993; 116:1477-1496.

52. Abboh KH, Martin AD. Surgical treatment of postherpetic neuralgia by subdermal denervation. Neurology 1951; 1:275-282.

53. Bonica JJ. The Management of Pain. Philadelphia, Lea \& Feibiger, 1953, pp 798-800, 861-867.

54. Browder J, Deveer JA. Herpes zoster a surgical procedure for the treatment of postherpetic neuralgia. Ann Surg 1949; 130:622-636

55. Combes FC, Canizares O, Simunagco S. Herpes zoster: Treatment of pain. J Invest Dermatol 1950; 14:53-56.

56. Russel WR, Espir MLE, Morganstern FS. Treatment of postherpetic neuralgia. Lancet 1957; 1:242-245.

57. Appleman DH. Treatment of Herpes Zoster with ACTH. N Engl J Med 1955; 253: 693-695.

58. Walsh TD. Antidepressant in chronic pain. Clin Neuropharmacol 1983; 6:171-195.

59. Kost RG, Straus SE. Postherpetic neuralgia - pathogenesis, treatment and prevention. N Engl J Med 1996; 335:32-42.

6o. Irani DN, Johnson RT. New approaches to the treatment of herpes zoster and postherpetic neuralgia. Infectious Medicine 1996; 13:897-902.

61. Woodforde JM, Dwyer B, McEwen BW et al. Treatment of post herpetic neuralgia. Med J Aust 1965; 2:869-872.

62. Kishore-Kumar R, Max MB, Schafer SC et al. Desipramine relieves post herpetic neuralgia. Clin Pharmacol Ther 1990; 47: 305-312.

63. Taub A. Relief of postherpetic neuralgia with psychotropic drugs. I Neurosurg 1973; 39:235-239.

64. Taub A, Collins WF. Observation on the treatment of degeneration of dysesthesia with psychotropic drugs. Adv Neurol 1974; 4:309-315.

65. Watson CPN, Evan RJ, Reed K et al. Amitriptyline vs. placebo in postherpetic neuralgia. Neurology 1982; 32:671-673.

66. Watson CPN. Therapeutic window for amitriptyline analgesia. Canad Med Asso J 1984; 130:105-106.

67. Max MB, Schafer SC, Culnane M et al. Amitriptyline, but not lorazepam, relieves post herpetic neuralgia. Neurology 1988; 38: 1427-1432.

68. Hatangdi VS, Boss RA, Richards EG. Postherpetic neuralgia: Management with antiepileptic and tricyclic drugs. In Bonica JJ, Fessards A (eds.): Advanced Pain Research and Therapy, New York, Raven Press, 1976; 1:583-579.

69. Konduer R. Use of psychotropic drugs for the treatment of chronic severe pain. In Bonica JJ Fessards A (eds.). Advanced Pain Research and Therapy, New York, Raven Press 1976; 10:579-582.

70. Carasso RL, Yehuda S, Strefler M. Clomipramine and amitriptyline in the treatment of severe pain. Int J Neurosci 1979; 9:191194.

71. Crue BL, Todd EM, Moline DB. Post herpetic neuralgia conservative treatment regimen. In Cure BL (ed.) Pain Research and Treatment. New York, Academic Press, 1975, pp 289-292.

72. Gerson GR, Jones RB, Luscombe DK. Studies on the concomitant use of carbamazepine and clomipramine for the relief of post herpetic neuralgia. Postgrad Med J 
1977; 53:104-109.

73. Raftery $\mathrm{H}$. The management of post herpetic pain using sodium valproate and amitriptyline. Ir Med J 1979; 72:399-401.

74. Swerdlow M. Anticonvulsant drugs and chronic pain. Clin Neuropharmacol 1982; 7:51-82.

75. Swerland $M$. The treatment of shooting pain. Postgrad Med J 1980; 56:159-161.

76. Killian JM, Fromm JH. Carbamazepine for treatment of neuralgia. Lancet 1957; 1 : 242-245.

77. Niv D, Ben-Ari S, Rappoport A et al. Post herpetic neuralgia - Clinical experience with a conservative treatment. Clin J Pain 1989; 5:295-300.

78. Rowbotham MC, Hardeb N, Stacey B et al. Gabapentin for the treatment of postherpetic neuralgia: A randomized controlled trial. J Am Med Assoc 1998; 280:18371842.

79. Watson CPN. The medical treatment of postherpetic neuralgia: antidepressants, anticonvulsants, opioids and practical guidelines for management. In Watson CPN, Gershon AA (eds.) Herpes Zoster and Postherpetic Neuralgia. $2^{\text {nd }}$ ed., New York, Elsevier Press, 2001, pp 243-254.

8o. Singh D, Kennedy $\mathrm{DH}$. The use of gabapentin for the treatment of postherpetic neuralgia. Clin Ther 2003; 25:852-889.

81. Pappagallo M, Haldey EJ. Pharmacological management of postherpetic neuralgia. CNS Drugs 2003; 17:771-780.

82. Dworkin RH, Corbin AE, Young JP Jr. et al. Pregabalin for the treatment of postherpetic neuralgia: randomized, placebo controlled trial. Neurology 2003; 60:12741283.

83. Ayres S, Mihan R. Post-herpes zoster neuralgia. Arch Dermatology 1973; 108:855856.

84. Perkins HM, Hanlon PR. Epidural injections of local anesthetics and steroids for the relief of pain secondary to herpes zoster. Arch Surg 1978; 113:253-254.

85. Colding A. Treatment of shingles (herpes zoster) with sympathetic blocking. Sygeplejersken 1972; 72:8-10.

86. Colding A. Treatment of pain: Organization of pain clinic treatment of acute herpes zoster. Proc R. Soc Lond 1973; 66:541543.

87. Masud KZ, Forster KJ. Sympathetic block in herpes zoster. Am Fam Physician 1975; 12: 142-143.

88. Forrest JB. Management of chronic dorsal root pain with epidural steroid. Can $A n$ aesth Soc J 1978: 25:218-225.

89. Epstein E. Treatment of zoster and postzoster neuralgia by the intralesional injec tion of triamcinolone: A computer analysis of 199 cases. Int J Dermat 1976; 15:762769.

90. Epstein E. Triamcinolone-Procaine in the treatment of zoster and post zoster neuralgia. Calif Med 1971; 115:6-10.

91. Tio R, Moya F, Vorasaran S. Treatments of post herpetic neuralgia. Anesth Sinica 1978; 16:151-153.

92. Rains C, Bryson HM. Topical capsaicin A review of its pharmacological properties and therapeutic potential in post herpetic neuralgia, diabetic neuropathy, and osteoarthritis. Drugs Aging 1995; 7:317328.

93. Litman SJ, Vitkun SA, Poppers RJ. Use of EMLA cream in the treatment of post-herpetic neuralgia. J Clin Anesth 1996; 8:5457.

94. De Benedittis G, Besana F, Lorenzetti A. A new topical treatment for acute herpetic neuralgia and post-herpetic neuralgia: the aspirin/diethyl ether mixture. An open-label study plus a double-blind controlled clinical trial. Pain 1992; 48:383-390.

95. De Benedittis G, Lorenzetti A. Topical aspirin/diethyl ether mixture versus indomethacin and diclofenac/diethyl ether mixtures for acute herpetic neuralgia and postherpetic neuralgia: a double-blind crossover placebo-controlled study. Pain 1996; 65:45-51.

96. Sokolowski P. Capsaicin in pain therapy. Wiad Lek 1994; 47:527-532.

97. Rowbotham MC, Davies PS, Fields HL. Topical lidocaine gel relieves postherpetic neuralgia. Ann Neurol 1995; 37:246-253.

98. Rowbotham MC, Davies PS, Verkempinck $C$ et al. Lidocaine patch: double-blind controlled study of a new treatment method for post-herpetic neuralgia. Pain 1996; 65:39-44.

99. Jessell TM, Iverson LL, Cuello AC. Capsaicin induced depletion of substance $P$ from primary sensory neurons. Brain Res 1978; 152:132-188.

10o. Otsuka M, Konishi S. Release of substance P-like immunoreactivity from isolated spinal cord of newborn rat. Nature 1976; 264 83-84.

101. Watson N, Evans RJ, Watt VR et al. Post herpetic neuralgia and topical capsaicin. Pain 1988; 33:333-340.

102. Stow PJ, Glynn CJ, Minor B. EMLA cream in the treatment of post-herpetic neuralgia. Efficacy and pharmacokinetic profile. Pain 1989; 39:301-305.

103. King RB. Topical aspirin in chloroform and the relief of pain due to herpes zoster and postherpetic neuralgia. Arch Neurol 1993; 50:1046-1053.

104. Moore KC. Laser therapy in post herpetic neuralgia. Presented to the British Medical Laser Association “241” Workshop and AGM, The Royal London Hospital, 1996.

105. Yaksich I, Tan LC and Previn V. Low energy laser therapy for treatment of post-herpetic neuralgia. Ann Acad Med Singapore 1993; 22:441-442.

106. Kageshima K, Wakasugi B, Shiotani M et al. Thoracic and lumbar sympathetic ganglion block for post herpetic neuralgia. Masui 1992; 41:106-110.

107. Eide K, Stubhaug A, Oye I et al. Continuous subcutaneous administration of the
$\mathrm{N}$-methyl-D-aspartic acid (NMDA) receptor antagonist ketamine in the treatment of post-herpetic neuralgia. Pain 1995; 61: 221-228.

108. Eide PK, Jorum E, Stubhaug A et al. Relief of post-herpetic neuralgia with the $\mathrm{N}$ methyl-D-aspartic acid receptor antagonist ketamine: A double-blind, cross-ove comparison with morphine and placebo. Pain 1994; 58:347-354.

109. Suzuki T, Kato J, Sacki S et al. Analgesic ef fect of dextromethorphan for postherpetic neuralgia. Masui 1996; 45:629-633.

110. Taverner D. Alleviation of post herpetic neuralgia. Lancet 1960; 2:671-673.

111. Nathan PD, Wall PD. Treatment of post herpetic neuralgia by prolonged electrical stimulation. Br Med J 1974; 3:645-647.

112. Haas LF. Post herpetic neuralgia, treatment and prevention. Trans Ophthalmol Soc N Z 1977; 29:133-136.

113. Long DM. External electrical stimulation as a treatment of chronic pain. Minn Med 1974; 57:195-198.

114. Friedman AH, Nashold BS. Dorsal root entry zone lesions for postherpetic neuralgia. Neurosurgery 1984; 70:96-97.

115. Payne C. Ultrasound for post herpetic neuralgia. A study to investigate the re sults of treatment. Physiotherapy 1984; 70:96-97.

116. Lewis AT, Field J, Madim D. Acupuncture compared with placebo in post herpetic pain. Pain 1983; 17:361-368.

117. Erikson DL, Long DM. Ten years follow up of dorsal column irritation. In Bonica J, Lindblom U, Iggo A (eds.) Advances in Pain Research and Therapy, New York, Raven, 1983; 5:583-590.

118. Hosobuchi Y. The current status of analgesic brain stimulation. Acta Neurichir 1980; 30:219-227.

119. Siegfried J. Monopolar electrical stimulation of nucleus ventroposteromedialis for postherpetic facial pain. Appl Neurophysiol 1982; 45:179-184.

120. Cushing $\mathrm{H}$. The major trigeminal neuralgias and their surgical treatment based on experience with 332 gasserian operations. Am J Med Sci 1920; 160:157-184.

121. White JC, Sweet WH. Pain and the Neurosurgeon: A Forty Year Experience. Springfield, Charles C. Thomas, 1969, pp 382384 .

122. Tindall GT, Odom GL, Vieth RG. Surgical treatment of post-herpetic neuralgia, results of skin undermining and excision in 14 patients. Arch Neurol 1962; 7:423-426

123. Richter HP, Seitz K. Dorsal root entry zone lesions for the control of deafferentation pain. Experience in ten patients. Neuro surg 1984; 15:956-959.

124. Saiki $M$, Kondo $A$, Kinuta $Y$ et al. Treatment of intractable postherpetic neuralgia and blepharospasm: intraneural injection of adriamycin. No Shinkei Geka 1995; 23: 125-130.

125. Friedman $\mathrm{AH}$, Nashold BS. DREZ lesions 
for relief of pain related to spinal cord injury. J Neurosurg 1986; 65:465-69.

126. Gorecki JP, Nashold BS. The Duke experience with the nucleus caudalis DREZ operation. Acta Neurochir Wien 1995; 64:128131

127. Rath SA, Braun V, Soliman N et al. Results of DREZ coagulations for pain related to plexus lesions, spinal cord injuries and postherpetic neuralgia. Acta Neurochir Wien 1996; 138:364-369.

128. Balfour HH. Acyclovir therapy for herpes zoster. Advantages and adverse effects JAMA 1986; 255:387-388.

129. McKendrick MW, McGill JI, Wood MJ. Lack of effect of acyclovir on post herpetic neuralgia. BMJ 1989; 298:431.

130. Tyring S, Barbarash RA, Nahlik JE et al. Famciclovir for the treatment of acute herpes zoster: Effects on acute disease and postherpetic neuralgia. A randomized, double-blind, placebo-controlled trial. Ann Intern Med 1995; 123:89-96.

131. Morton P, Thomson AN. Oral acyclovir in the treatment of herpes zoster in general practice. N Z Med I 1989; 102:93-95.

132. DeGreef H. Famciclovir, a new oral antiherpes drug: results of the first controlled clinical study demonstrating its efficacy and safety in the treatment of uncomplicated herpes zoster in immunocompetent patients. Int J Antimicrobial Agents 1995; 4:241-246.

133. Esmann V, Geil JP, Kroon S et al. Prednisolone does not prevent post-herpetic neuralgia. Lancet 1987; 2:126-129.

134. Keczkes K, Basheer AM. Do corticosteroids prevent post herpetic neuralgia? $\mathrm{Br} J$ Dermatol 1980; 102:551-555.

135. Clemmensen OJ, Andersen KE. ACTH versus prednisone and placebo in herpes zoster treatment. Clin Exp Dermatol 1984; 9: 557-563.
136. Nakamura T, Yokoo H, Hamakawa T et al. Preemptive analgesia produced with epidural analgesia administered prior to surgery. Masui 1994; 43:1024-1028

137. Winnie AP, Hartwell PW. Relationship between time of treatment of acute herpes zoster with sympathetic blockade and prevention of post-herpetic neuralgia: Clinical support for a new theory of the mechanism by which sympathetic blockade provides therapeutic benefit. Reg Anesth 1993; 18:277-282.

138. Ali NM. Does sympathetic ganglionic block prevent postherpetic neuralgia? Reg Anesth 1995; 20:227-233.

139. Niv D, Devor M. Preemptive analgesia in the relief of postoperative pain. Curr Rev Pain 1996; 1:79-92.

140. Niv D. Intraoperative treatment of postoperative pain. Pain 1996 - An updated review. In Campbell JN (ed): IASP Refresher Course Syllabus. IASP Press, Seattle, pp 173-187. 
